\title{
Do Centro Histórico à Cidade Histórica: a dimensão do projeto de conservação - o caso da cidade de Roma*
}

\section{Dal Centro Storico alla Città Storica: la dimensione progettuale della conservazione - Il caso di Roma}

\author{
Elio TRUSIANI ${ }^{1}$
}

\section{O Plano Regulador de Roma: breves considera- ções introdutórias}

Mais de quarenta anos depois do Plano Regulador de 1962, a prefeitura municipal de Roma adotou em 5 de março de 2003 o novo Plano Regulador. O percurso para a formação desse plano durou sete anos de estudos para aprofundar o conhecimento sobre o imenso território municipal $\left(1300 \mathrm{~km}^{2}\right)$ e finalizar o processo de planejamento que havia iniciado com oPlano das Certezas, adotado em 1997, como primeira etapa do novo processo de planificação da Prefeitura Municipal de Roma.

O Plano Regulador conclui, portanto, um trabalho iniciado com o Plano das Certezas: este levava em consideração e definia o caráter estrutural do território como a cidade consolidada, incluindo em seu interior o centro histórico, as partes externas para tutelar, enquanto, para a cidade em transformação, condiciona cada decisão a um novo instrumento. Com a adoção do plano, Roma teve finalmente uma nova perspectiva para construir seu desenvolvimento inserido em um sistema histórico-ambiental tutelado e valorizado, base concreta da sustentabilidade, com vistas à reorganização funcional e espacial das estruturas implantadas. Pensava-se em uma cidade projetada em uma dimensão metropolitana e organizada segundo um modelo policêntrico.
As principais inovações introduzidas pelo novo plano urbanístico tratam, primeiramente, de um modelo organizador do território. O novo plano adota um conceito baseado em um sistema de centralidades difusas, articuladas em dois níveis: metropolitano e local. As centralidades metropolitanas (aproximadamente vinte) são implantadas em correspondência aos nós dos sistemas de comunicação, de modo a constituir uma rede de relações físicas e nãomateriais que respondam às exigências da metrópole contemporânea. Essas centralidades são destinadas a acolher as funções e os serviços que a cidade oferece, seja nacional/internacionalmente ou no território da Província e de Região. Por outro lado, as centralidades locais (aproximadamente cinqüenta) são destinadas aos habitantes de um entorno urbano mais bem limitado e definido.

As intervenções ligadas ao policentrismo remetemse à requalificação da periferia, que diz respeito não só à realização de infra-estruturas e serviços hoje inexistentes, mas sobretudo à descentralização de funções valorizadas (de pesquisa, universidades, cultura, turismo, comércio, residências), contidas nas novas centralidades metropolitanas.

A tutela do território avança por aproximadamente 87.000 hectares e a campagna romana (campo) não é considerada somente um território não-urbanizado reservado à produção agrícola, mas sim parte fundamental de um sistema ambiental completo submetido, portanto, a um

\footnotetext{
* Tradução de Gisele Maucini Gomes.

1 Elio Trusiani, Arquiteto, Doutor em Urbanismo, ensina como Professor Titular na Faculdade de Arquitetura da Universidade de Roma La Sapienza e na Faculdade de Arquitetura de Ascoli Piceno da Universidade de Camerino.
} 
TRUSIANI, E. Do Centro Histórico à Cidade Histórica: a dimensão do projeto de...

atento planejamento de proteção e valorização dos elementos que o constituem.

Um outro elemento inovador é o método de leitura da cidade, não mais por zonas homogêneas - superadas a partir da década de setenta-mas por tecidos, o que permite substituir o modo de tratamento unitário para zonas inteiras e ler, ao invés, as diferenças - sobretudo em uma cidade como Roma - e portanto compreender as atuais exigências de transformação, de reprojetação de partes existentes da cidade, onde se verificam fenômenos de abandono e de perda de qualidade. Essa medida permitiu a superação do velho conceito de "centro histórico", ligado à parte mais antiga do centro urbano e a elevação ao conceito de "cidade histórica", que compreende um universo mais vasto e difundido no território (da Idade Média ao séc. XX).

Mais um aspecto que diferencia o Plano Regulador é a tentativa de se incluir nes se plano as intervenções ordinárias introduzidas pela normativa nacional e pelos decretos ministeriais dos anos 90 . Isto é, o plano engloba, na sua normativa técnica de atuação, os instrumentos que fazem parte da definição da "família dos programas complexos".

\section{De Centro Histórico a Cidade Histórica}

A passagem do conceito de Centro Histórico ao conceito de Cidade Histórica ${ }^{2}$ significou superar uma idéia defensiva e cristalizante, dando lugar a uma intensa atenção às potencialidades evolutivas de um patrimônio qualificado, que só agora vem sendo absorvido em sua essência sistêmica, apto a individuar seletivamente na descontinuidade e na possibilidade de integração.

Essa escolha reabriu, com determinação, um importante debate sobre a relação entre conservação e transformação, ou ainda entre as duas dimensões intrínsecas ao conceito de tradição, cuja dialética foi a força motriz da evolução da forma urbana. Isso foi feito admitindo-se na definição de "cidade histórica" tanto o sistema de valores quanto o sistema de funções, nas recíprocas consolidações e em uma perfeita integração entre qualidade e quantidade. A integração pretendida a partir do centro histórico é admiti-lo como polarização urbana a partir da qual partem sistemas radiais ou radiocêntricos, de natureza seja histórico-morfológica, seja funcional e dinâmica.

Uma polarização antiga, sobrevivente ao tempo, agora inserida em um novo desenho de policentrismo metropolitano do qual pode constituir uma das centralidades, de fato configura-se como a centralidade das centralidades, visto que se torna a concentração de sistemas de valores e de funções e também porque a tradição ali depositou um investimento simbólico e psicológico.

Para não perder os aspectos essenciais da conservação, foi estudado um modelo fundamentado na integração de duas categorias de intervenção: uma de tipo regulador e uma de tipo programático. A primeira é reservada aos tecidos ${ }^{3}$ urbanos homogêneos, dotados por si só de uma qualificação histórico-morfológica consolidada, enquanto a segunda é ligada a âmbitos urbanos estratégicos pela ativação de dinâmicas transformadoras.

A dimensão reguladora do plano se baseia em uma descrição e regulamentação da cidade histórica que se liga à escala intermediária da malha urbana; esta é considerada a escala mais idônea para consolidar as qualidades estruturadoras da forma urbana herdada, mas ao mesmo tempo capaz de recuperar, primeiramente, a escala das morfologias de implantação e, posteriormente, aquela do edifício isolado e do espaço aberto elementar, a partir também de uma dimensão discursiva, que suporta a certeza das regras com a flexibilidade interpretativa dos possíveis percursos de conhecimento e de projeto.

Os Âmbitos de Programação Estratégica ${ }^{4}$ sintetizam o resultado da busca de uma instrumentação de projeto capaz de reconduzir a um quadro de coerência, fatos urba-

\footnotetext{
2 Por Cidade Histórica entende-se o sistema integrado constituído pela área histórica central interna à muralha; a expansão urbana entre os anos 800 e 900 d.C. consolidada interna e externamente à muralha; e pelos sítios isolados localizados no território comunal que apresentam uma identidade histórico-cultural definida, de particular qualidade, reconhecível do ponto de vista do caráter morfogenético e estruturante da implantação urbana, bem como do caráter morfotipológico, arquitetônico e de uso do solo.

3 Se entende por tecido da Cidade História, construções planas ou parte destas construções que constituem uma agregação de edifícios, com relação ao espaço aberto incluso e excluso da rede viária, reconduzindo às normas de sustentabilidade homogênea de implantação, subdivisão do solo, disposição e referências com relação ao traçado onde devem prevalecer características tipológicas, figurativas, técnico-estruturais e funcionais. Acessado tais tecidos ou edifícios seriados ou que tenham especiais experimentos, colocam-se normas próprias do tecido de aparência

4 Os ambientes de programação estratégica constituem a linha estrutural da cidade histórica, como um grande sistema integrado.
} 
TRUSIANI, E. Do Centro Histórico à Cidade Histórica: a dimensão do projeto de..

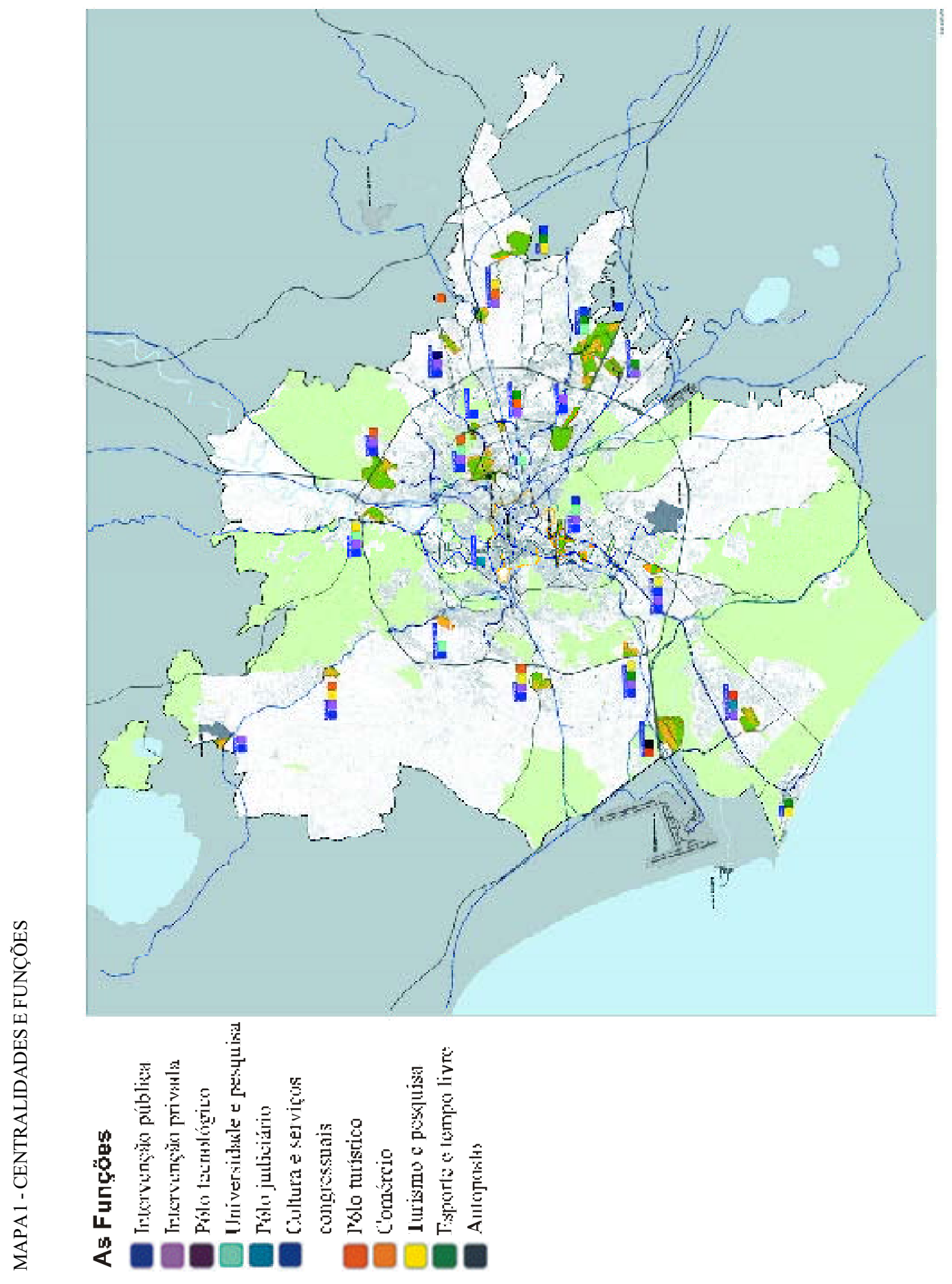


TRUSIANI, E. Do Centro Histórico à Cidade Histórica: a dimensão do projeto de..

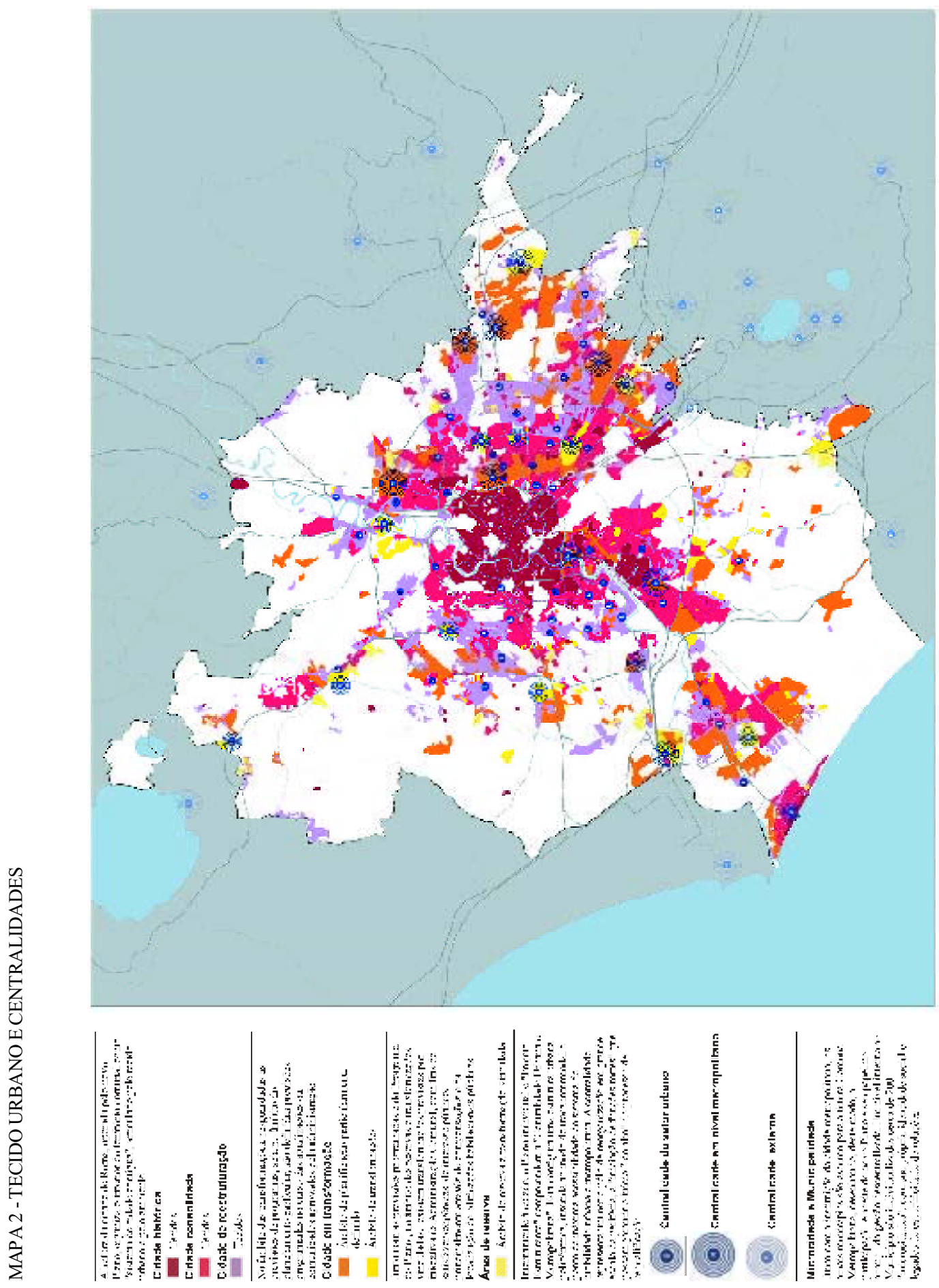


TRUSIANI, E. Do Centro Histórico à Cidade Histórica: a dimensão do projeto de...

nos pertencentes a diversas categorias analíticas e normativas, mas ligadas por nexos racionais estruturantes, referentes ao "duplo sistema" dos valores e das funções. Os âmbitos individualizados são cinco: dois deles têm um caráter morfogenético originário e atravessam toda a cidade de norte a sul, em direção ao mar: o âmbito Tevere (rio Tibre) e o âmbito do eixo norte-sul. Dois deles têm um caráter estrutural e radiocêntrico: o âmbito da muralha e o âmbito do cinturão ferroviário. Por fim, o âmbito que é especificamente arqueológico, monumental e ambiental do setor sudoeste, e é constituído pelo sistema dos Fóruns Imperiais, pela área arqueológica de Caracolla e pela Appia Antica. São cinco traços de contornos urbanos, densos de histórias descobertas e prefigurações, nas quais a maior força dos materiais e das escolhas de valorização solicitam modificações físicas, funcionais e de sentido dos materiais mais frágeis.

A passagem do centro histórico à cidade histórica, portanto, não significa homogeneizar tudo o que existe e tratar diversamente o que está fora do seu perímetro, mas significa reconhecer as diferenças que caracterizam as diversas partes; saber descrevê-las e conservá-las, e simultaneamente sugerir, onde necessário, as modificações compatíveis com essas diferenças. Isto quer dizer pesquisar relações novas e estratégicas entre as partes, seja dentro da cidade histórica, seja entre esta e a cidade a ser consolidada e transformada. Esse fundamento do Plano Regulador é resultado de uma operação de ligação com um processo iniciado há muitos anos, a partir de uma multiplicidade de estudos, pesquisas, programas e projetos que nos últimos anos percorreram essa estrada e sobre ela começaram a raciocinar. Primeiramente vem a Prefeitura Municipal, que com sua experiência durante as juntas Argan e Petroselli concentrou a própria atenção sobre a cidade post-unitaria, produzindo planos e projetos que faziam alusão a uma necessária extensão do campo, além dos estreitos limites da muralha, avançando com hipóteses de novos princípios da conservação e valorização. Nesse sentido, o Plano organizou, de um lado, o patrimônio de análise, estudos, pesquisas, programas e projetos produzidos nestes últimos anos e, de outro lado, fez um salto em direção a um processo de consolidação de novos princípios da valorização e conservação. Na verdade, tentou conferir ou restituir ao termo "cidade histórica" o difícil dever de regular a valorização, orientar as estratégias de requalificação e construir as condições do projeto.

Assistimos a uma revisão do pensamento da história nos instrumentos urbanísticos, e das modalidades por meio das quais um plano deve mudar, para contar não só com uma condição prescritiva mas também com a necessidade de descrever a cidade e as suas histórias passadas e futuras em termos diferentes daqueles que a lei contempla. No Plano de Roma, como dito anteriormente, convivem dois modos de descrever e de governar a cidade, sua conservação e transformação, que se integram, mas que também mantêm uma necessária e fértil autonomia.

Seja na dimensão reguladora, seja na dimensão estrutural e estratégica, insistiu-se noreconhecimento do papel central de uma dimensão de projeto da conservação e valorização da cidade histórica: o projeto de reconhecimento de tantos e diversos edifícios e espaços abertos ${ }^{5}$ que o projeto implícito da sobreposição histórica permite e que a vitalidade dos processos nos obriga a considerar na individualidade do caso a caso, dentro das coordenadas reguladoras das descrições interpretativas produzidas. Ao mesmo tempo, a explícita modificação e valorização dos muitos lugares da cidade histórica, que demandam uma redescoberta e uma nova dimensão do sentido no sistema de relações espaciais, perceptivas, ecológicas e funcionais dos grandes sinais da natureza e da história definem a dimensão estrutural e estratégica do plano.

O contorno da cidade histórica se faz pelo tecido urbano e espaços abertos, diferentemente do que se fazia anteriormente com a tradicional cor unitária indicativa da zona do centro histórico; este liga incisivamente as diversas modalidades de agregação, disposição e conformação morfológica, arquitetônica e construtiva de edifícios e espaços abertos relacionados com as diferentes fases históricas que formaram o espaço e, portanto, às diversas culturas do habitar e do espaço urbano, restituindo a projetação em curso à cidade histórica, ele mesmo fundamento da noção de cidade.

5 São espaços abertos da Cidade Histórica todo aquele componente que se constitui como um sistema "vazio", unicamente com algumas partes construídas, em razão de seu reconhecimento, ou da composição histórica-morfológica-arquitetônica e da conotação do caráter figurativo e ecológico-ambiental, participando da definição da identidade da cidade. 
TRUSIANI, E. Do Centro Histórico à Cidade Histórica: a dimensão do projeto de...

A dimensão do projetual da conservação resulta portanto evidente e é, ao mesmo tempo, elemento fundamental para se alcançar a sustentabilidade urbanística, ${ }^{6}$ a qual é parte importante - se não determinante-do patrimônio histórico-ambiental. Realmente, são essas regras da gestão do patrimônio edificado existente (o tecido urbano) e da transformação urbanística (âmbitos e centralidades): os novos índices e parâmetros urbanísticos e ecológicos reduzem sensivelmente o encargo urbanístico em respeito às modalidades com as quais foi realizada a cidade moderna (densidade, alturas, etc.) e a regra geral domix funcional garante um ambiente urbano sempre habitável e nunca segregado. Afirma-se o princípio de que também a transformação urbanística, isto é, o objeto principal do plano urbanístico de hoje, e não só a conservação, pode garantir a melhora das condições ecológicas da cidade, na ótica de um desenvolvimento sustentável, e que essa melhoria pode ser valorizada em termos objetivos, a partir de um balanço qualitativo dos recursos ambientais fundamentais de interesse para a transformação, alem do respeito à disponibilidade e acessibilidade das áreas relativas.

Assim sendo, não é só standard, mas uma melhor qualidade do ar, do equilíbrio do ciclo da água, a recuperação do solo poluído, o reforço da biodiversidade são os portadores de uma transformação urbanística que incide concretamente sobre a qualidade do ambiente.

\section{Breves considerações}

Em resumo, o Plano Regulador individualiza na política da tutela e da proteção, além do princípio da conservação, uma ação não só passiva de regime puramente de vínculos, mas fortemente inovadora em termos de proporção e de relação com a modificação e com a transformação, reconhecendo no sistema das diferenças o valor da história da cidade, entendida como processo de estratificação de fatos urbanos e de usos e ações comportamentais, o valor fundamental para um projeto sustentável do ambiente urbano, natural e físico.

Portanto, a tutela e a proteção não mais entendidos somente como limite ao novo, mas como estímulo para ele, e fundamento para os processos urbanos de consolidação, ou simplesmente, adequação da cidade segundo o processo em ação que se move do centro histórico à cidade existente, e ainda, ao território histórico. Um processo é um percurso cultural no qual o reconhecimento dos valores do patrimônio histórico serve como ponto de partida para o projeto da cidade histórica e contemporânea, onde o conceito de conservação e recuperação é subentendido também como transformação, repropondo a importância do projeto de cidade segundo uma visão mais ampla que saiba colher, ler e interpretar as mudanças vindouras e conjugá-las com as reais exigências de transformação e sustentabilidade urbanística.

\footnotetext{
6- O conceito de "sustentabilidade urbanística" é a representação mais significativa da integração entre a urbanística e a ecologia na mais recente experiência de planificação na Itália. Ela contempla um objetivo explícito de multiplanos de última geração da normativa regional dos últimos anos. Estes elementos de normatização têm caracterizado esta integração de sustentabilidade urbanística em geral, modificando de modo substancial o modelo ambiental precedente em dois aspectos: - a superação da própria tutela e a conservação como um horizonte fundamental do plano urbanístico-ambiental e a compatibilização ambiental do sistema infra-estrutural. Em síntese a sustentabilidade urbanística é concretizada em três aspectos fundamentais:

a) a exclusão de novas formas de expansão urbana, orientando o plano para a manutenção qualitativa (recuperação e complementação) e a transformação da cidade existente, evitando o mais possível posteriores consumo de solo extra-urbano;

b) a compatibilidade ambiental e ecológica do sistema de infra-estrutura com novas soluções para a mobilidade urbana, privilegiando o transporte urbano coletivo e a redução dos impactos (ruídos, paisagem), na infra-estrutura de mobilidade, enquanto resguarda a rede tecnológica, a relativa compatibilidade ambiental que comporta a separação da rede limpa ou de esgoto, a absorção direta da água pluvial através da manutenção do solo permeável para evitar o sobrecarregamento do sistema de esgoto, a exclusão de nova sobrecarga na zona urbana provida pela eficiente rede hídrica e de esgoto, etc.;

c) a aplicação do princípio da regeneração ambiental em todas as intervenções de atuação do plano com operações de recuperação das áreas impermeabilizadas do solo, legando uma manutenção da cidade existente e sua transformação urbanística; a difusão massiva do verde privado, o aumento do verde público, a garantia da elevação da cota de superfície permeável para as novas edificações, a criação de uma rede ecológica que conjugue os elementos ambientais, naturais e artificiais, presentes interna e externamente na cidade.
} 